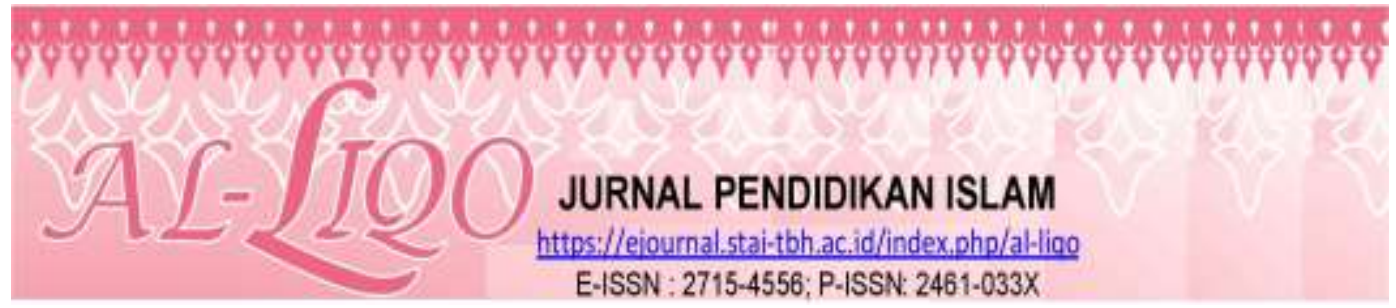

\title{
METODE QAWAID DAN TARJAMAH DALAM MEMAHAMI KITAB KUNING
}

\author{
Mulyadi $^{1)}$ \\ 1)Dosen Tetap Program Studi Pendidikan Agama Islam STAI Auliaurrasyidin Tembilahan \\ Kabupaten Indragiri Hilir Propinsi Riau. Email : mulyadi@stai-tbh.ac.id
}

\begin{abstract}
Abstrak
Qawa'id adalah aturan-aturan baku yang telah menjadi konsensus para linguis dan harus diikuti oleh pemakai bahasa serta dikonsedarisasikan dengan penutur aslinya, sedangkan Tarjamah adalah menyalin atau memindahkan dari suatu bahasa ke dalam bahasa lain. Oleh karena, setiap siswa hendaknya dilatih untuk menghafal kaidah-kaidah nahwu dan sharaf dengan diawali menghafal materi nazham banyak di pakai dalam kitab-kitab nahwu dan sharaf seperti Kitab al-Jurumiyah, 'Imrithi, dan Alfiyah dan lain sebagainnya. Rumusan masalah yaitu; Konsep dasar dan karakteristik metode qawa'id dan tarjamah, kekuatan dan kelemahan metode qawa'id dan tarjamah, langkah-langkah presentasi metode qawa'id dan tarjamah, contoh kongkret materi dalam pelaksanaan metode qawa'id dan tarjamah pada pembelajaran kitab kuning.
\end{abstract}

Kata Kunci : Metode Qawaid, Tarjamah, Kitab Kuning

\section{PENDAHULUAN}

Bahasa Arab merupakan materi pelajaran yang memiliki kaitan yang sangat erat dengan agama Islam, karena semua ajaran Islam terhimpun dalam AlQur'an dan dilengkapi dengan penjelasan Al-Hadits. Untuk dapat mengkaji dan mendalami ajaran Islam, harus mempelajari Al-Qur'an dan Al-Hadis. Dan agar dapat mempelajari Al-Qur'an dan Al-Hadits dibutuhkan kemampuan bahasa Arab yang memadai." "Bahkan salah satu syarat untuk menafsirkan ayat Al-Qu'an adalah harus menguasai bahasa Arab"2.

Kekurangan yang ada pada umat Islam Indonesia saat ini adalah sedikitnya cendikiawan muslim yang mampu membaca dan memahami kitab kuning. Karena membaca dan mepelajari kitab kuning memang tidak mudah, untuk bisa membaca dan mepelajarinya dibutuhkan beberapa persyaratan, antara lain

${ }^{1}$ Imam Makruf, Strategi Pembelajaran Bahasa Aktif, (Semarang: Need's Press, 2009), h. 7

2 Abdudin Nata, "Tafsir Ayat-ayat Pendidikan", (Jakarta: PT. Raja Grafindo Persada, 2010), h. 3 
mengerti ilmu Nahwu, Sharaf, dan Balaghah, dan harus menguasai tata bahasa Arab. Tidak cukup hanya menguasai bahasa Arab-nya saja, sebab kita tidak akan bisa memahami suatu bahasa tanpa dilengkapi dengan ketatabahasaannya. ${ }^{3}$

Berdasarkan itulah maka orang yang hendak memahami hukum-hukum (ajaran) agama Islam dengan baik, haruslah berusaha mempelajari bahasa $\mathrm{Arab}^{4}$. Dan perlu juga memperhatikan teknik pengajaran yang sesuai dengan kemampuan anak didik.

Pondok pesantren merupakan sebuah lembaga pendidikan yang memberikan andil yang sangat besar terhadap perkembangan pendidikan di Indonesia, dari sebelum kemerdekaannya, sampai sekarang ini ekspansi pesantren masih dapat dilihat baik di pedesaan maupun perkotaan. ${ }^{5}$ Keberadaan pesantren itu sendiri ada polarisasi dalam sistem pendidikannya yaitu ada sistem tradisional dan ada sistem moderen. Berbagai bentuktransfer ilmu terjadi berbagai macam cara, seperti pengajian kitab klasik dengan metode-metodenya. ${ }^{6}$

Faktor yang paling dominan dalam perkembangan pendidikan di pondok pesantren adalah penerapan metode pembelajarannya. Keberlangsungan pembelajaran akan baik, manakala kyai atau gurunya memahami berbagai metode atau cara bagaimana materi itu diinternalisasikan kepada santrinya. Dalam proses pembelajaran seorang kiyai atau para guru dituntut untuk menguasai metode pembelajaran yang tepat untuk santrinya, termasuk dalam metode pembelajaran kitab klasik yang dikenal tanpa harakat ( $k i t a b$ gundul ${ }^{7}$ ), yang harus dikenali oleh siswa kata demi kata dan tata bahasanya.

3 Syaikh Syamsuddin Muhammad Arra'ini, Ilmu Nahwu Tarjamahan Mutammimah Ajurumiyah, (Bandung: Sinar Baru Algensindo, 2013), h. v-vi

${ }^{4}$ Azhar Arsyad, Bahasa Arab Dan Metode Pengajarannya, (Yogyakarta: Pustaka Pelajar, 2004), h.7

${ }^{5}$ Nurcholish Madjid, Bilik-Bilik Pesantren, (Jakarta: Paramadina, 1997), h. xxii-xxiii

${ }^{6}$ Ilmu Dan Aplikasi PendidikanPendidikan Disiplin Ilmu Bagian IV, (PT. Imperial Bhakti Utama, 2007), h. 440

${ }^{7}$ Kitab Gundul; maksudnya tulisan Arab yang tidak menggunakan harakat atau baris. (Zamakhsyari Dhofir, Zamakhsyari Dhofir, Tradisi Pesantren, Studi Pandangan Hidup Kyai dan Visinya Mengenai Masa Depan Indonesia, (Jakarta: LP3ES, Cetakan kesembilan, 2011), h. 55 
Kedudukan guru di pesantren memiliki dua fungsi; sebagai latihan penumbuhan kemampuannya untuk menjadi kiai di kemudian hari dan sebagai pembantu kiai dalam mendidik para siswa. ${ }^{8}$

Tugas dan tanggung jawab atas pendidikan Islam di sekolah tidak hanya pada guru agama saja, tetapi merupakan tanggung jawab sekolah secara keseluruhan. Lingkungan sekolah harus mendukung dan menjadi laboratorium bagi pengajaran pendidikan agama.

Dalam melaksanakan pendidikan agama faktor-faktor yang menentukan berhasil atau tidaknya pendidikan agama tersebut dalah "Anak didik, Pendidik, Tujuan pendidikan, Alat-alat pendidikan, Lingkungan". 9 Dalam suatu proses belajar mengajar, ada dua unsur yang sangat penting adalah metode mengajar dan media pembelajaran. Kedua aspek ini saling berkaitan. Pemilihan metode mengajar akan mempengaruhi jenis media pembelajaran yang sesuai, meskipun masih ada berbagai aspek lain yang harus diperhatikan. ${ }^{10}$

Apabila kita perhatikan dalam proses perkembangan pendidikan agama Islam di Indonesia, bahwa salah satu gejala negatif sebagai penghalang yang paling menonjol dalam pelaksanaan pendidikan agama ialah masalah metode mengajar atau mendidik agama. Meskipun metode tidak akan berarti apa-apa bila dipandang terpisah dari komponen-komponen lain, dengan pengertian bahwa metode baru dianggap penting dalam hubungannya dengan semua komponen pendidikan lainnya, seperti tujuan, materi, evaluasi, situasi dan lain-lain.

Oleh karena itu, dalam pelaksanaan pendidikan agama diperlukan suatu pengetahuan tentang methodologi pendidikan agama, dengan tujuan agar setiap pendidik agama dapat memperoleh pengertian kemampuan mendidik agama yang dilengkapi dengan pengetahuan dan kecakapan profesionil. ${ }^{11}$

Metode qawaid dan tarjamah memiliki peran dalam menanamkan pemahaman tantang tata bahasa, melatih menulis, melatih siswa untuk

\footnotetext{
${ }^{8}$ Abdurrahman Wahid, Mennggerakkan Tradisi, (Yogyakarta: PT. LkiS, Printing Cemerlang, 2010), h. 20

9 Zuhairini,et al, Methodik Khusus Pendidikan Agama, (Surabaya: Usaha Nasional, 1983),h. 28

${ }^{10}$ Azhar Arsyad, Media Pembelajaran, (Jakarta: PT. Raja Grafindo Persada, 2009), h.15

${ }^{11}$ Zuhairini, et al, Op.Cit h. 79-80
} 
mendapatkan makna dengan tarjamah yang tepat. ${ }^{12}$ Metode qawa'id dan tarjamah mempunyai asumsi bahwa tata bahasa merupakan bagian dari filsafat dan logika. Belajar dengan demikian dapat meningkatkan kemampuan berfikir logis memecahkan masalah, dan menghafal. Para pelajar bahasa dengan metode qawa'id dan tarjamah didorong untuk menghafal tek-tek klasik berbahasa Arab dan terjamahnya dalam belajar terutama tek-tek yang bernilai sastra tinggi. ${ }^{13}$

Tujuan metodeqawa'id dan tarjamah ini adalah agar siswa pandai dalam menghapal dan memahami tata bahasa, memahami, dan menterjamah, bahasa Arab ke dalam bahasa sehari-hari atau sebaliknya. ${ }^{14}$

\section{METODE PENELITIAN}

Jenis penelitian menggunakan pendekatan deskriptif kualitatif yang penulis gunakan adalah library research yaitu mengumpulkan buku-buku yang berkaitan dengan objek penelitian atau penelitian yang bersifat kepustakaan.

1. Sumber Data

Kajian yang penulis gunakan adalah penelitian perpustakaan murni, penulis akan menggunakan dua sumber, yaitu:

a. Sumber Primer

Sumber data yang berifat primer adalah buku rujukan awal dan utama dalam penelitian, sumber primer yang penulis gunakan adalah :

i. Ahmad Fuad Effendy, Metodologi Pengajaran Bahasa Arab, (Malang: Misykat, 2004)

ii. Acep Hermawan, Metodologi Pembelajaran Bahasa Arab, (Bandung: PT. Remaja Rosdakarya, 2010)

iii. M. Zaka Al-Farisi, Pedoman Penerjamahan Arab Indonesia, (Bandung: PT Remaja Rosdakarya, 2011), h. 21

\footnotetext{
${ }^{12}$ Zulkifli, Metodologi Pengajaran Bahasa Arab; Konvensional dan Kontemporer, (Yokyakarta: Nusa Medi, 2011), h. 11

${ }^{13}$ Ahmad Fuad Effendy, Metodologi Pengajaran Bahasa Arab, (Malang: Misykat, 2004), h. 31

${ }^{14}$ Acep Hermawan, Metodologi Pembelajaran Bahasa Arab, (Bandung: PT. Remaja Rosdakarya,2010), h. 171
} 
iv. Muhammad Raid Naufal, الرموز النحوية التنى /ستعملها /هل اللغة الجاوية), (Sugihan Tuban, Hidayatussalam, $\mathrm{tt}$ ), tanpa halaman.

v. Syaikh Syamsuddin Muhammad Arra'ini, Ilmu Nahwu Tarjamahan Mutammimah Ajurumiyah, (Bandung: Sinar Baru Algensindo, 2013)

b. Sumber Sekunder

Sumber sekunder adalah hasil pengumpulan yang dilakukan oleh orang lain dengan maksud tertentu dan mempunyai kategori atau klasifikasi menurut keperluan masing-masing dan kegunaan bagi peneliti masingmasing. ${ }^{15}$ Dalam hal ini Sumber data yang berifat sekunder adalah buku rujukan pendukung dalam penelitian, sumber sekunder yang penulis gunakan adalah :

i. Abdudin Nata, “Tafsir Ayat-ayat Pendidikan”, (Jakarta: PT. Raja Grafindo Persada, 2010)

ii. Abdurrahman Wahid, Mennggerakkan Tradisi, (Yogyakarta: PT. LkiS, Printing Cemerlang, 2010)

iii. Departemen Pendidikan Nasional, Kamus Besar Bahasa Indonesia Pusat Bahasa, Edisi Keempat, (Jakarta: PT. Gramedia, 2013)

iv. Imam Makruf, Strategi Pembelajaran Bahasa Aktif, (Semarang: Need's Press, 2009)

v. M. Zaka Al-Farisi, Pedoman Penerjamahan Arab Indonesia, (Bandung: PT Remaja Rosdakarya, 2011), h. 21

vi. M. Ridlwan Qoyyum Sa'id, Rahasia Sukses Fuqoha, (Blok H. 05 Lirboyo Kediri: Mitra Gayatri, 2006)

2. Teknik Pengumpulan Data

Teknik pengumpulan data adalah cara-cara yang digunakan oleh peneliti untuk mengumpulkan data. ${ }^{16}$ Pengumpulan data dalam penelitian 5 , h. 143

${ }^{15}$ S. Nasotion, Metode Research Penelitian Ilmiah, (Jakarta: Bumi Aksara, 2002), Cet.

16 Riduwan, Skala Pengukuran Variabel-Variabel Penelitian, (Bandung: Alfabeta, 2013), Cet. Ke-10, h. 24 
ini adalah dengan cara dokumentasi. Dokumentasi adalah "ditujukan untuk memperoleh data langsung dari tempat penelitian, meliputi bukubuku yang relevan, peraturan-peraturan, laporan kegiatan, foto-foto, fim, dokumenter, data yang relevan penelitian". ${ }^{17}$

3. Teknik Analisa Data

Teknik analisa data adalah cara penghitungan untuk menjawab rumusan masalah dan pengujian hipotesis yang diajukan. ${ }^{18}$ Hipotesis adalah jawaban sementara yang harus di uji kebenarannya. Namun, penelitian yang penulis gunakan dengan kajian pustaka (library research) ini, maka penulis menggunakan tekhnik analisa data kajian isi (countent analysis).

Kajian ini adalah kajian yang menanfaatkan buku atau dokumen untuk menarik kesimpulan, baik kajian isi yang bersifat deduktif maupun kajian isi yang bersifat induktif. ${ }^{19}$ Pada kajian ini peneliti terlebih dahulu mengadakan survei data untuk memperoleh informasi dari penelitian terdahulu terhadap pengerjaan tanpa memperdulikan apakah data itu primer atau sekunder, di lapangan atau dilaboratorium. Kemudian, menelusuri leteratur yang ada serta mentelaahnya secara tekun. Setelah itu, peneliti mengungkapkan buah pikiran secara kritis dan analistis. ${ }^{20}$

\section{PEMBAHASAN}

\section{Qawa'id}

Kata qawa'id“قوقاعد"، "قدة"،, berbentuk kata jamak dari kata mufrad , secara etimologis artinya adalah "pondasi, dasar, alas, peraturan" ${ }^{21}$.Sedangkan qawa'id secara terminologis adalah "aturan-aturan baku yang telah menjadi

${ }^{17}$ Ibid., h. 31

18 Riduan, Belajar Mudah Penelitian Untuk Guru, Karyawan Dan Peneliti Pemula, (Bandung: Alfabeta, 2015). h. 12

${ }^{19}$ Lexy J. Moleong, Metodologi Penelitian Kualitatif (Bandung:Remaja Rosdakarya, 2013), Cet. 31, h. 220

${ }^{20}$ Moh. Nazir, Metode Penelitian, (Bogor Selatan: Ghalia Indonesia, 2005), h. 93

${ }^{21}$ Ahmad Warson Munawwir, Loc.Cit, h. 1138 
konsensus para linguis, dan harus diikuti oleh pemakai bahasa serta dikonsedarisasikan dengan penutur aslinya". ${ }^{22}$

\section{Tarjamah}

Tarjamah "secara bahasa artinya adalah "tarjamah atau tafsiran". ${ }^{23}$ Di dalam kamus besar bahasa Indonesia disebutkan bahwa menterjamahkan berarti "menyalin atau memindahkan dari suatu bahasa ke dalam bahasa lain"24. "Penerjamahan adalah proses pengalihan suatu teks tulis atau lisan ke dalam bahasa lain". ${ }^{25}$

Sebagian para pakar mengemukakan bahwa metode qawa'id dan tarjamah memiliki beberapa nama lain, yaitu metode klasik (at-thariqah qadimah), dan metode tradisional (at-thariqah taqlidiyah). Karena metode ini memfokuskan kajian terhadap teks bahasa dan informasi sekitar kebahasaan yang mengacu kepada ekplanasi qawa'id, kosakata serta menampilkan praktik fungsi bahasa dalam format dialog dan problematika situasi kehidupan. De Saussmle menegaskan bahwa bahasa merupakan kolektivitas unsur kosa kata atau kalimat (isim, huruf, dan fi'il), disamping nahwu dan sharaf yang memiliki hirarkis antar unsur-unsur dimaksud. ${ }^{26}$

\section{Konsep Dasar dan Karakteristik Metode Qawa'id Dan Tarjamah}

Asumsi yang mendasari metode qawa'id dan tarjamah ini adalah suatu logika semesta yang menyatakan bahwa semua bahasa didunia ini adalah sama, dan tata bahasa adalah cabang dari logika. Untuk melihat titik kesamaan itu perlu dipelajari dan dikaji, dan untuk melihat pokok pikiran yang terkandung oleh tulisan bahasa asing yang dipelajari perlu diadakan kegiatan penerjamahan kosakata atau kalimat dalam bahasa pelajar sehari-hari. jadi inti kegiatan belajar bahasa asing adalah menganalisa tata bahasa, menulis kalimat, dan menghafal kosakata sebagai dasar transformasinya ke dalam bahasa sehari-hari.

\footnotetext{
${ }^{22}$ Zul-Hannan, Loc.Cit, h. 112

${ }^{23}$ Ahmad Warson Munawwir, Loc.cit, h. 131

${ }^{24}$ Departemen Pendidikan Nasional, Kamus Besar Bahasa Indonesia Pusat Bahasa, Edisi Keempat, (Jakarta: PT. Gramedia, 2013), h.1452

${ }^{25}$ M. Zaka Al-Farisi, Pedoman Penerjamahan Arab Indonesia, (Bandung: PT Remaja Rosdakarya, 2011), h. 21

${ }^{26}$ Zul-Hannan, Op.Cit, h. 31
} 
Ada dua pendekatan teori yang mendasari pengajaran bahasa, yaitu teori tata bahasa tradisional dan struktural. Teori tata bahasa tradisional melihat bahasa secara priskriptif, artinya bahasa yang baik dan benar adalah menurut ahli bahasa, bukan yang digunakan oleh penutur asli yang di lapangan. Berbeda dengan teori struktural melihat bahasa secara deskriptif, artinya bahasa yang baik dan benar adalah yang digunakan oleh penutur asli yang di lapangan. Metode qawa'id dan tarjamah melihat bahasa secara priskriptif, dengan demikian kebenaran bahasa berpedoman kepada petunjuk tertulis, yaitu yang sesuai sengan aturan-aturan gramatikal yang ditulis oleh ahli bahasa, bukan menurut ukuran guru. Ba'labaki menjelaskan bahwa dasar pokok metode ini adalah hapalan kaidah, analisis gramatika terhadap wacana, dan menterjamah. Dengan demikian, ada dua aspek terpenting dalam metode qawa'id dan tarjamah pertama, kemampuan menguasai kaidah tata bahasa; dan kedua, kemampuan menterjamah. $^{27}$

Dari konsep dasar tersebut beberapa karakteristik metode qawa'id dan tarjamah terkait dengan proses pembelajaran bahasa Arab yaitu:

1. Lebih menekankan pada kemampuan membaca, menulis, dan menerjamah.

2. Mengunakan terjamah sebagai bentuk paling mendasar dalam pembelajaran.

3. Lebih menekankan pada analisis nahwu dari ungkapan-ungkapan bahasa yang diucapkan. $^{28}$

4. Kosakata tergantung kepada bacaan yang telah disajikan

5. Materi pelajaran terdiri dari hafalan kaidah-kaidah gramatika, penerjamahan kata-kata tanpa konteks, penerjamahanteks-teks pendek, kemudian penafsiran teks.

6. Latihan ucapan dan pengunaan bahasa tidak diberikan, jika diberikan hanya sekali saja.

\section{Kekuatan Dan Kelemahan Metode Qawa'id Dan Tarjamah}

\section{a. Kekuatan}

1. Metode ini sangat besar perhatiannya terhadap keterampilan membaca.

\footnotetext{
${ }^{27}$ Acep Hermawan, Metodologi Pembelajaran Bahasa Arab, (Bandung: PT. Remaja Rosdakarya, 2010), h. 170-171

${ }^{28}$ Imam Makruf, Op.Cit, h.49
} 
2. Metode ini menggunakan bahasa ibu bagi peserta didik, sebagai medium vital dalam proses pembelajaran bahasa sasaran.

3. Metode ini sangat sangat memperhatikan qawa'idsecara general, sebagai medium pembelajaran bahasa Arab yang akurat dan benar.

4. Metode ini digunakan pendidik dan peserta didik untuk menganalisis qawaid bahasa secara.

\section{b. Kelemahan}

1. Metode ini mengabaikan keterampilan berbicara (kalam), di mana keterampilan ini merupakan keterampilan yang pokok.

2. Metode ini sering menggunakan bahasa ibu sebagai bahasa pengantar dalam proses pembelajaran, sehingga bahasa sasaran tidak tercapai maksimal.

3. Metode ini sangat memerhatikan pengajaran ilmu tentang bahasa Arab, bukan bahasanya itu sendiri. ${ }^{29}$

\section{Langkah-Langkah Presentasi Metode Qawa'id Dan Tarjamah}

Langkah-langkah penerapanmetode qawa'iddan tarjamah adalah:

1. Pendahuluan, memuat berbagai hal yang berkaitan dengan materi yang diajarkan baik berupa apersepsi, tes awal tentang materi atau yang lainnya. ${ }^{30}$

2. Guru dan siswa masing-masing memegang buku (kitab), guru membaca dan mengartikan kata demi kata atau kalimat demi kalimat ke dalam bahasa daerah khas pesantren yang telah didekatkan kepada sensivitas bahasa Arab.

3. Santri mencatat arti setiap kata atau kalimat Arab yang diucapkan artinya oleh guru. Pekerjaan santri mencatat arti setiap kata ini dikenal dengan istilah memberi "jenggot", karena terjamahan yang dicantumkan di bawah kata Arab tadi ditulis menjulur ke bawah menyerupai jenggot. ${ }^{31}$

4. Guru menjelaskan materi pelajaran dengan menjelaskan difinisi kaidah-kaidah tertentu dalam bahasa Arab yang harus dihapalkan sesuai dengan materi yang akan disajikan, berikut terjamahannya dalam bahasa pelajar. Contoh: Jika

\footnotetext{
${ }^{29}$ Ibid., h. 50

${ }^{30}$ Acep Hermawan, Op.Cit, h. 173

${ }^{31}$ Ahmad Fuad Efendy, Op.Cit, h. 22-23
} 
materi yang akan disajikan mengandung kaidah mubtada-khabar, maka langkah yang mungkin dilakukan adalah :

a. Mengenalkan konsep mubtada-khabar berikut definisi keduanya kedalam bahasa pelajar.

b. kemudian menampilkan beberapa contoh konkrit.

c. Setelah itu guru memberi penjelasan contoh-contoh seperlunya.

5. Setelah peserta didik faham konsep mubtada-khabar, Guru membimbing untuk menghafalkan definisinya dengan disiplin.

6. Jika ada kosakata yang dipandang sulit diterjamahkan guru menjelaskan kosakata.

7. Guru meminta peserta didik mendemonstrasikan hafalan kosakata yang telah diajarkan sebelumnya.

8. Guru memberikan teks bahasa Arab, kemudian meminta mereka untuk memahami isi bacaan dengan menerjamahkannya kata demi kata, kalimat demi kalimat, sampai paragra paragra demi paragraf. Dalam hal ini peserta didik diharapkan dapat mengidentifikasi mubtada-khabar, sebagaimana yang telah mereka hafalkan, lalu menganalisis sampai detail. Hal ini bertujuan agar terjamahan mereka benar-benar dapat menerjamahkan teks sesuai dengan kaidah bahasa yang benar. ${ }^{32}$

9. selanjutnya membetulkan hasil tarjamahan mereka yang salah, dan menerangkan sektor qawa'id (Nahwu-Sharaf) dari aspek keindahan bahasanya. Pada waktu lain pendidik meminta peserta didik untuk melakukan analisis qawa'id. ${ }^{33}$

10. sebagai kegiatan akhir, pendidik memberi pekerjaan rumah yang berupa persiapan tarjamahan untuk dibahas pada pertemuan berikutnya. ${ }^{34}$

\section{Contoh Kongkret Materi Dalam pelaksanaan metode qawa'id dan tarjamah Pada Pembelajaran Kitab Kuning}

Berikut ini adalah contoh konkrit materi pembelajaran bahasa Arab:

a. Contoh Materi Kitab Kuning (Nahwu dan Sharaf)

\footnotetext{
${ }^{32}$ Acep Hermawan, Loc.cit, h. 173-174

${ }^{33}$ Zul-Hannan, Op.cit, h. 33

${ }^{34}$ Acep Hermawan, Loc.cit, h. 174
} 


$$
\begin{aligned}
& \text { الكلمة و أقسامها } \\
& \text { الكلمة: لفظ يدل على معنى مفرد. و هي ثلاثة أقسام: اسح, وفحل, وحرف. } \\
& \text { الإسم: مادل على معنى في نفسه غير مقترن بزمان: كخالد وفرس و عصفور } \\
& \text { ودار وحنطة وماء. و الفعل مادل على معنى في نفسه مقترن بزمان: كجاء ويجيئ } \\
& \text { وجيء. و الحرف مادل على معنى في غيره مثل: هل وفي ولم و على و إنْ ومنْ. } \\
& \text { المبتدأ و الخبر } \\
& \text { المبتدأ هو اسم مرفوع في أول جملة. والخبر هو اسم مرفوع يكون مع المتدأ } \\
& \text { جملة مفيدة } \\
& \text { الأمثلة: الثفاحة حلوة, الصورة جميلة, الجرى مفيد, القطار سريع, النظافة و اجب, الارض } \\
& \text { مستدير . } \\
& \text { فالبحث: الأسماء الأولى (النفاحة, الصورة, الجرى, القطار, النظافة, الأرض) من } \\
& \text { الجمل السبقة تسمى "مبتدأ". و الأسماء الثانية (حلوة, جمبلة مفيد, سريع, و اجب, } \\
& \text { مستدير)من الجمل السبقة تسمى "خبر ا". و إذاتأملنا آخر كل اسم من الإسمين } \\
& \text { في كل جملة من الجمل السبقةوجدناه مرفو عا.35 }
\end{aligned}
$$

Para siswa juga dilatih untuk menghafal kaidah-kaidah nahwu di luar kepala. Untuk memudahkan hafalan materi nazham banyak di pakai seperti Kitab 'Imrithi, dan Alfiyah yang sangat dikenal di pondok pesantren di Indonesia. ${ }^{36}$ Contoh beberapa bait dari kitab Alfiyah adalah:

$$
\begin{aligned}
& \text { كلامنا لفظ مفبد كاستقم \# و واسم وفعل ثم حرف الكلم } \\
& \text { و احده كلمة والقول عم \# وكلمة بها كلام قد يعم37 } \\
& \text { و الاسم منه معرب ومبني \# }
\end{aligned}
$$

Contoh konkrit diatas adalah merupakan sistem pembelajaran bahasa Arab melalui metode qawaid dan tarjamah dengan menggunakan pendekatan Istiqraiyah dan Qiyasiyah. Pendekatan Istiqraiyah adalah pendekatan yang teknis pembelajarannya dimulai dengan menampilkan beberapa contoh kalimat, kemudian langkah selanjutnya merumuskan kaidah qawaid.

\footnotetext{
${ }^{35}$ Zul-Hannan, Op.Cit., h. 34-35

${ }^{36}$ Ahmad Fuad Efendy, Op.Cit, h. 35

${ }^{37}$ Misbah Mushtafa, Mishbahul-Hawalik fi Syarhi Alfiyati Ibni Malik, (Bangilan Tuban,TT), h. 7-8.

${ }^{38}$ Ibid, h. 14
} 
Sedangkan pendekatan Qiyasiyah adalah pendekatan yang teknis pembelajarannya dimulai dengan menghafalkan qawaid, selanjutnya menampilkan beberapa contoh kalimat. ${ }^{39}$

b. Contoh Materi Kitab Kuning selain Nahwu Dan Sharaf

Pelaksanaan metode qawa'id dan tarjamah ala pesantren ini adalah model penerjamahan yang sekaligus mengajarkan tata kalimat (qawa'id)yaitu menggunakan kata-kata tertentu sebagai simbul yang menunjukkan fungsi suatu kata dalam kalimat.

Contoh kalimat: الحمد لله ربالعا لمين,diterjamahkan model pesantren sebagai berikut;

الحمد: Utawi sekabehe puji = bermula segala puji

لله: Iku kagungane gusti Allah = itu hanya milik Allah

رب العالمين:Kang Mengerani sak alam kabeh = yang merajai semua alam

Kata "utawi, iku, kang" dalam terjamahan tersebut digunakan bukan dalam arti sebenarnya, melainkan sebagai kata pinjaman fungsional, yaitu untuk menunjukkan fungsi kata dalam kalimat. Utawi, sebagai simbol untuk kata yang berfungsi sebagai subjek (mubtada', simbulnya; "p"); Iku, sebagai simbol untuk kata yang berfungsi sebagai prediket (khabar, simbulnya; "خ"); dan kang, sebagai simbol untuk kata sifat (na'at, simbulnya; "ن"yang dipakai secara atributif.

Pengajara bahasa Arab bentuk ini adalah yang paling dominan di tanah air dan diakui kontri businya dalam memahamkan umat Islam Indonesia terhadap ajaran agamanya. ${ }^{40}$

c. Simbul Yang Menunjukkan fungsi kata (qawa'id) Yang di Pergunakan Dalam penerjamahan Kitab Kuning Model Pesantren Tradisional.

${ }^{39}$ Zul-Hannan, Loc.Cit, h. 35

${ }^{40}$ Ahmad Fuad Efendy, Loc.cit, h.23 


\begin{tabular}{|c|c|c|c|c|}
\hline & \multicolumn{4}{|c|}{$\begin{array}{c}\text { الرموز النحوية } \\
\text { (Rumus Nahwu) }\end{array}$} \\
\hline o & $\begin{array}{l}\text { Huruf } \\
\text { Simbul } \\
\text { الرموز }\end{array}$ & $\begin{array}{l}\text { Nama Tarkib } \\
\text { yang } \\
\text { Dirumuskan }\end{array}$ & $\begin{array}{l}\text { Tempat } \\
\text { Rumus }\end{array}$ & $\begin{array}{r}\text { Contoh-Contoh } \\
\text { (الأمثلة) }\end{array}$ \\
\hline & r & مبتدأ & Diatas & زيد قُائر \\
\hline &.$^{41} \dot{\tau}$ & خبره & Diatas & زيد قائم \\
\hline & فا & فاعل عاقل & Diatas & فام زيد \\
\hline & ف & فاعل غير & Diatas & أكل الغنم \\
\hline & نفا & نائب الفاعل & Diatas & 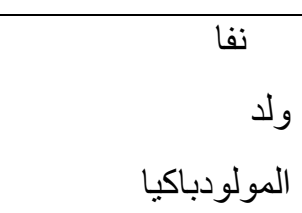 \\
\hline & ف & نائب الفاعل & Diatas & إذا زلزلت \\
\hline & مـ & مفعول بها & Diatas & ضرب زيد \\
\hline & $\varepsilon$ & مفعول معه & Diatas & جاء \\
\hline & م & مفعول & Diatas & جئت إجلالا \\
\hline
\end{tabular}

${ }^{41}$ M.Ridlwan Qoyyum Sa’id, Rahasia Sukses Fuqoha, (Blok H. 05 Lirboyo Kediri: Mitra Gayatri, 2006), h.12 


\begin{tabular}{|c|c|c|c|c|}
\hline 0 & b & مفعول & Diatas & مط موسم الله \\
\hline 1 & b & ظرف & Diatas & ظأكل زيدا \\
\hline o & $\begin{array}{l}\text { Huruf } \\
\text { simbul } \\
\text { الرموز }\end{array}$ & $\begin{array}{c}\text { Nama Tarkib } \\
\text { YangDirumuska } \\
n\end{array}$ & $\begin{array}{l}\text { Tempat } \\
\text { Rumus }\end{array}$ & $\begin{array}{c}\text { Contoh-Contoh } \\
\text { (الأمنلة) }\end{array}$ \\
\hline 2 & ظ & ظرف & Diatas & جلست فوق \\
\hline 3 & ص & صلة & Diatas & و الذين كفروا \\
\hline 4 & ن & نعت & Diatas & جاء زيد \\
\hline 5 & با & بيان & Diatas & ـ مالا تعلمون \\
\hline 6 & بد & بدل & Diatas & نفعني زيد \\
\hline 7 & ش & شرطية & Diatas & 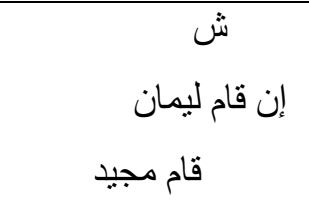 \\
\hline 8 & ج & جواب & Diatas & $\begin{array}{c}\text { إن قام سليمان } \\
\text { قام مجيد } \\
\text { قان }\end{array}$ \\
\hline
\end{tabular}




\begin{tabular}{|c|c|c|c|c|}
\hline 9 & حا & حال & Diatas & جاء زيد وحده \\
\hline 0 & س س & سبيبيّة & Diatas & ذللك بما \\
\hline 1 & $\varepsilon$ & تعليل & Diatas & وجاهدو افيل ع الله \\
\hline 2 & $\dot{\varepsilon}$ & غاية & Diatas & 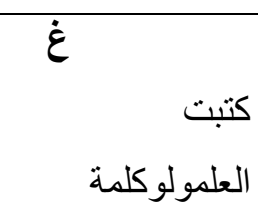 \\
\hline 3 & J & لملك & Diatas & الثوب لزيد \\
\hline 4 & ما & اختصاص & Diatas & أطعبت \\
\hline 5 & م & مصدرية & Diatas & نـ نـر زيد مالم \\
\hline 6 & تم & تمييز & Diatas & تُ \\
\hline 7 & ن & نفى & Diatas & مابخل محمد \\
\hline 8 & s & مفضّل عليه & Dibawah & مع العمأفضلمنالمال \\
\hline 9 & ج & جمع & Dibawah & جيت الجنود \\
\hline
\end{tabular}




\begin{tabular}{|c|c|c|c|c|}
\hline 0 & ن & نهي & Dibawah & لاتفحل \\
\hline 1 & ${ }^{\dot{\tau}}$ & خبر مطلق & Dibawah & $\begin{array}{r}\text { لاثو اب لكافر } \\
\text { خ }\end{array}$ \\
\hline 2 & $\therefore$ & ضمير شأن & Dibawah & $\therefore$ \\
\hline 4 & ى & لام ابتداء & Dibawah & بخنيل \\
\hline 5 & سد ف & لعل تأكيد & Dibawah & سفهم \\
\hline 6 & ش & شرطيّة & Dibawah & شلما مات \\
\hline 7 & مـ & مصدر & Dibawah & 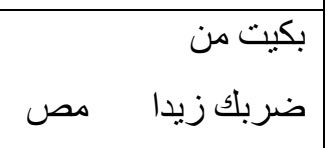 \\
\hline 8 & د & دعاء & Dibawah & فال علي كرم اللهوجهه \\
\hline 9 & ى & عطاف بيان & Dibawah & جاء عمر \\
\hline 0 & 1 & الله & Dibawah & أنها يعذب 1 أكفار 1 \\
\hline 1 & s & محمد & Dibawah & و على أهل بيتهوسلم \\
\hline 2 & با & نسبة & Dibawah & قال محمدنوويالمالكي با \\
\hline
\end{tabular}

Buku reverensi ${ }^{42}$

${ }^{42}$ Muhammad Raid Naufal, الرموز النحوية التى استعدها / هل اللغة الجاوية, (Sugihan Tuban, Hidayatussalam, tt), tanpa halaman. 


\section{KESIMPULAN}

Qawa'id merupakan aturan-aturan baku yang telah menjadi konsekwensi dan harus diikuti oleh pemakai bahasa serta dikonsedarisasikan dengan penutur aslinya. Sedangkan Tarjamah adalah proses pengalihan suatu teks tulis atau lisan ke dalam bahasa lain. Sebagian para pakar mengemukakan bahwa metode qawa'id dan tarjamah memiliki beberapa nama lain, yaitu metode klasik (atthariqah qadimah), dan metode tradisional (at-thariqah taqlidiyah). Karena metode ini memfokuskan kajian terhadap teks bahasa dan informasi sekitar kebahasaan yang mengacu kepada kosakata serta menampilkan praktik fungsi bahasa dalam format dialog dan problematika situasi kehidupan. disamping itu nahwu dan sharaf juga harus dikuasai dalam memahami kalimat dimaksud kalimat (isim, huruf, dan fi'il).

Oleh karena, Para siswa hendaknya dilatih untuk menghafal kaidah-kaidah nahwu dan sharaf di luar kepala. Untuk memudahkan hafalan materi nazham banyak di pakai seperti Kitab al-Jurumiyah, 'Imrithi, dan Alfiyah yang sangat dikenal di pondok pesantren di Indonesia.

\section{DAFTAR PUSTAKA}

Abdudin Nata, "Tafsir Ayat-ayat Pendidikan", (Jakarta: PT. Raja Grafindo Persada, 2010)

Azhar Arsyad, Bahasa Arab Dan Metode Pengajarannya, (Yogyakarta: Pustaka Pelajar, 2004)

Abdurrahman Wahid, Mennggerakkan Tradisi, (Yogyakarta: PT. LkiS, Printing Cemerlang, 2010)

Azhar Arsyad, Media Pembelajaran, (Jakarta: PT. Raja Grafindo Persada, 2009)

Ahmad Fuad Effendy, Metodologi Pengajaran Bahasa Arab, (Malang: Misykat, 2004)

Acep Hermawan, Metodologi Pembelajaran Bahasa Arab, (Bandung: PT. Remaja Rosdakarya, 2010)

Departemen Pendidikan Nasional, Kamus Besar Bahasa Indonesia Pusat Bahasa, Edisi Keempat, (Jakarta: PT. Gramedia, 2013) 
Imam Makruf, Strategi Pembelajaran Bahasa Aktif, (Semarang: Need's Press, 2009)

Lexy J. Moleong, Metodologi Penelitian Kualitatif (Bandung:Remaja Rosdakarya, 2013), Cet. 31

M. Zaka Al-Farisi, Pedoman Penerjamahan Arab Indonesia, (Bandung: PT Remaja Rosdakarya, 2011), h. 21

Misbah Mushtafa, Mishbahul-Hawalik fi Syarhi Alfiyati Ibni Malik, (Bangilan Tuban,TT)

M. Ridlwan Qoyyum Sa'id, Rahasia Sukses Fuqoha, (Blok H. 05 Lirboyo Kediri: Mitra Gayatri, 2006)

Muhammad Raid Naufal,الرموز النحوية النى /ستعكلها أهل اللغة الجاوية, (Sugihan Tuban, Hidayatussalam, $\mathrm{tt}$ ), tanpa halaman.

Moh. Nazir, Metode Penelitian, (Bogor Selatan: Ghalia Indonesia, 2005)

Nurcholish Madjid, Bilik-Bilik Pesantren, (Jakarta: Paramadina, 1997)

Riduwan, Skala Pengukuran Variabel-Variabel Penelitian, (Bandung: Alfabeta, 2013), Cet. Ke-10

Riduan, Belajar Mudah Penelitian Untuk Guru, Karyawan Dan Peneliti Pemula, (Bandung: Alfabeta, 2015)

Syaikh Syamsuddin Muhammad Arra'ini, Ilmu Nahwu Tarjamahan Mutammimah Ajurumiyah, (Bandung: Sinar Baru Algensindo, 2013)

S. Nasotion, Metode Research Penelitian Ilmiah, (Jakarta: Bumi Aksara, 2002), Cet. 5

Zamakhsyari Dhofir, Tradisi Pesantren, Studi Pandangan Hidup Kyai dan Visinya Mengenai Masa Depan Indonesia, (Jakarta: LP3ES, Cetakan kesembilan, 2011)

Zuhairini,et al, Methodik Khusus Pendidikan Agama, (Surabaya: Usaha Nasional, 1983)

Zulkifli, Metodologi Pengajaran Bahasa Arab; Konvensional dan Kontemporer, (Yokyakarta: Nusa Medi, 2011) 